\title{
El destino de los ingresos del Patrimonio Municipal del Suelo a la luz de la Ley $7 / 2002$, de 17 de Diciembre, de Ordenación Urbanística de Andalucía
}

\author{
María Luisa Arcos Fernández \\ Licenciada en Derecho \\ Técnico Urbanista \\ Jefe del Servicio de Gestión Urbanística \\ de la Gerencia de Urbanismo de Sevilla
}

Con la entrada en vigor el 20 de enero de 2003 de la Ley de Ordenación Urbanística de Andalucía, Ley 7/2002, de 17 de diciembre, se ha dado respuesta a un esperado respaldo legislativo de determinadas figuras que estaban vigentes en el urbanismo de otras Comunidades Autónomas (agente urbanizador, reservas de $\mathrm{VPO}, .$. ) y que no podíamos poner en práctica en nuestra Comunidad por falta del marco legislativo apropiado.

Una vez en vigor la citada Ley y congratulándonos por ello, son muchos los interrogantes que nos plantea su aplicación en la práctica, máxime si tenemos en cuenta la continua y en algunos casos excesivas remisiones a un posterior desarrollo reglamentario sobre todo en el ámbito de la ejecución del planeamiento.

Un tema que se ha planteado y que no podemos esperar a un desarrollo reglamentario que pueda arrojarnos claridad en ello al no estar así previsto es en sede del Patrimonio Municipal del Suelo, y en concreto sobre los destinos de los ingresos que procedentes de los bienes del Patrimonio Municipal del Suelo, que como sabemos, pasan a integrarse en él por aplicación del principio, característico de esta Institución, de retroalimentación, también llamado de subrogación real.

Es por ello, por lo que entendemos que es una problemática que debe resolverse mediante una interpretación de las normas que regulan la Institución. 
En esa línea, avanzamos en este artículo el planteamiento de la cuestión y una respuesta al mismo basada, como decimos, en una interpretación deducida de las normas que regulan esta institución, sin desconocer y así lo recogemos al final del artículo que existen ya otras opiniones distintas sobre la cuestión suscitada.

Pasemos, a continuación a desarrollar el planteamiento.

$\mathrm{El} \operatorname{art}^{\mathrm{o}} 75$ de Ley $7 / 2002$, de 17 de diciembre, de Ordenación Urbanística de Andalucía, que es el que regula la cuestión indica literalmente "Destino de los bienes integrantes de los Patrimonios Públicos de Suelo"

1.- "Los terrenos y construcciones integrantes de los Patrimonios Públicos de Suelo se destinarán..."

El segundo apartado, lo dedica al destino de los recursos económicos, y así indica: "LLos ingresos, asi como los recursos derivados de la propia gestión de los patrimonios públicos de suelo, se destinarán a:

a) Con carácter preferente, la adquisición de suelo destinado a viviendas de protección oficial u otros regimenes de protección pública.

b) La conservación, mejora, ampliación, urbanización y, en general, gestión urbanistica de los propios bienes del correspondiente patrimonio público de suelo.

c) La promoción de viviendas de protección oficial u otros regímenes de protección pública.

d) La ejecución de actuaciones públicas o el fomento de actuaciones privadas, previstas en el planeamiento, para la mejora, conservación y rehabilitación de zonas degradadas o de edificaciones en la ciudad consolidada".

Sin duda de los destinos descritos en este apartado, el que más nos llama la atención por su novedad y por constituir un auténtico "cajón de sastre" es el recogido en el apartado d). El resto, como veremos más adelante, se encajan a la perfección en lo que han sido desde siempre las finalidades propias y originarias de los Patrimonios Municipales de Suelo. .

Para conocer la aplicación práctica de este apartado, su contenido y límites y, en definitiva, su alcance es necesario, con carácter previo, hacer un breve análisis de cómo ha quedado la regulación de esta institución, los Patrimo- 
nios Municipales de Suelo, a la luz de la nueva regulación recogida en nuestra reciente legislación autonómica y para ello debemos de partir, centrando la cuestión y, como no podía ser de otra manera, del examen constitucional que a la legislación estatal vigente en esta materia, TRLS de 1992, Real Decreto Legislativo 1/1992, de 26 de junio, se realizó por la Sentencia del Tribunal Constitucional, 61/1997, de 20 de marzo.

La sentencia 61/1997, vino a indicar para esta Institución que “...tan sólo aquellas normas básicas que respondan efectivamente y estrictamente a la planificación general de la actividad económica, podrían encontrar cobijo en el referido título (competencial), que impide la producción de normas que, aunque relacionadas con esa planificación general, no guarden esa inmediata y directa relación con la dirección de la economía. Desde esta perspectiva, podría encontrar cobertura en el citado título estatal la mera determinación de la existencia de una figura como la que contempla el art ${ }^{\circ} 276$ del TRLS destinada a los Patrimonios Municipales de Suelo". Centrada así la cuestión, esta sentencia del Alto Tribunal declara inconstitucionales los $\operatorname{art}^{\circ} 277$ y 278.1 del TRLS de 1992, al regular el primero de ellos los bienes que integran el Patrimonio Municipal del Suelo y las reservas de suelo al ser competencia uno y otro tema de la regulación detallada que ha de quedar a la libre configuración de la Comunidad Autónoma.

Asimismo declara inconstitucional por no corresponder al Estado en el esquema constitucional de distribución de competencias entre el Estado y la Comunidad Autónoma, "la regulación el art ${ }^{o} 280.2$ al ser un desarrollo del principio general del destino de aquellos bienes. No así ocurre con el art ${ }^{o} 280.1$ que regula los destinos de ese Patrimonio: "construcción de viviendas sujetas a algún régimen de protección pública o al otros usos de interés social", artículo que junto con el 276 vinculado a la planificación de la actividad económica (art ${ }^{\circ}$ 149.1.13 CE) en relación con la vivienda (art $\left.{ }^{\circ} 4 \mathrm{CE}\right)$ y por tanto, al tener estos preceptos el carácter de básico, será la Comunidad Autónoma, la Administración competente para legislar sobre el desarrollo de esas bases."

Hasta aquí y partiendo del panorama legislativo del TRLS de 1992, los aspectos de la Institución de los Patrimonios Municipales de Suelo que han de ser regulados y están regulados por el Estado por su carácter básico, los arto 276 y 280.1 del TR de la Ley del Suelo de 1992.

Transcribimos a continuación los citados preceptos:

Artículo 276 1.- "Los Ayuntamientos que dispongan de planeamiento general deberán constituir su respectivo Patrimonio Municipal del Suelo, con la finalidad de re- 
gular el mercado de terrenos, obtener reservas de suelo para actuaciones de iniciativa pública facilitar la ejecución del planeamiento.

2.- Los bienes del Patrimonio Municipal del Suelo, constituyen un patrimonio separado de los restantes bienes municipales y los ingresos obtenidos mediante enajenación de los terrenos o sustitución del aprovechamiento correspondiente a la Administración por su equivalente en metálico, se destinarán a la conservación y ampliación del mismo".

Art' 280.1 "Lo bienes del Patrimonio Municipal del Suelo, una vez incorporado al proceso de urbanización y edificación, deberán ser destinados a la construcción de viviendas sujetas a algún régimen de protección pública o a otros usos de interés social de acuerdo con el planeamiento. “

Por tanto, a los efectos de la cuestión que se nos plantea este es el panorama legislativo a nivel estatal que como decimos tienen carácter básico tras la reiterada sentencia del Tribunal Constitucional.

Ahora bien, por tener estos preceptos carácter básico su desarrollo corresponde a las Comunidades Autónomas.

En nuestra Comunidad Autónoma tras la promulgación y posterior entrada en vigor de la Ley 7/2002, de 17 de diciembre, de Ordenación Urbanística de Andalucía, el pasado 20 de enero, la institución de los Patrimonios Públicos de Suelo ha quedado regulada de la siguiente forma:

Partimos en este análisis de lo que dispone la propia Exposición de Motivos de la Ley andaluza, indicando como más destacable de ésta al respecto los siguientes apartados:

Se establece "que en desarrollo del mandato constitucional, art" $47 \mathrm{CE}$, y desde el entendimiento del urbanismo como una función pública, en esta Ley se avanza en los mecanismos de intervención pública en el mercado de suelo, con el objetivo de que dicha intervención sirva para regular, en aras del interés general, los precios del suelo en un mercado generalmente caracterizado por su carácter alcista y la escasa flexibilidad de la oferta...

Para conseguirlo mantienen en la Ley los instrumentos ya existentes... y particularmente, se legisla sobre los patrimonios públicos de suelo, institución de debe constituir no sólo los municipios, sino también la Administración de la Junta de Andalucía a fin de dotarse de recursos para la actuación urbanistica pública en su sentido más amplio, pero manteniendo la prioridad de su destino a viviendas protegidas." 
Y en cuanto a la institución de los patrimonios públicos de suelo se indica "...por una parte se amplian los destinos de los bienes constituidos por los patrimonios públicos de suelo a actuaciones de mejora de la ciudad, y especialmente en áreas que requieren una intervención integración de rehabilitación..."

"Asimismo con el objetivo de dotar a dichas Administraciones de suelo para desarrollar las políticas urbanisticas públicas, esta Ley fija como participación de la Comunidad en las plusvalías generadas por la acción urbanística el máximo permitido por la legislación estatal".

Son claves para el entendimiento de cuál es la finalidad de una Institución, como la de los Patrimonios Municipales de Suelo en la nueva legislación autonómica de nuestra Comunidad, expresiones tales como “...se avanzan en los mecanismos de intervención pública en le mercado de suelo, con el objetivo de regular los precios del suelo...”, “... se amplían los destinos de los bienes que constituyen los patrimonios públicos...”, “...se legisla sobre los Patrimonios Públicos de Suelo a fin de dotarlos de recursos para la actuación urbanística en sentido amplio, pero manteniendo la prioridad de viviendas protegidas".

Por tanto, de la Exposición de Motivos de la Ley de Ordenación Urbanística de Andalucía y posteriormente del articulado que dedica a esta materia, Título III y en concreto su Capítulo I bajo el epígrafe de "Los Patrimonios Públicos de Suelo" y algunas otras referencias, en preceptos enmarcados en el ámbito de otras materias, como son los artºs. 52 relativo al destino de la prestación compensatoria en suelo no urbanizable, art ${ }^{\circ} 30$ relativo a las cesiones de aprovechamiento urbanístico correspondiente a la Administración urbanística, art 197 "Destino de las multas", etc., etc., se pueden deducir dos características básicas que determinan la regulación que se da a esta Institución, en la nueva Ley de Ordenación Urbanística de Andalucía:

- Se produce un fortalecimiento de la Institución del Patrimonio Municipal del Suelo mediante el apoderamiento de mayores recursos (prestación compensatoria del suelo no urbanizable, multas por infracciones urbanísticas).

- Se propugna la consolidación y potenciación de la institución como medida o vía de intervención en el mercado de suelo para incidir en los precios de éste, y por ende, en el de las viviendas.

A estas dos características habría que añadir una tercera nota característica: se amplían los fines a los que puede destinarse los recursos económicos 
de los Patrimonios Públicos de Suelo si bien con las matizaciones que más adelante veremos.

Esta última nota característica la encontramos en la determinación reco-

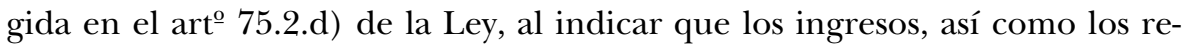
cursos de la propia gestión de los patrimonios públicos de suelo, se destinarán entre otros, a: "La ejecución de las actuaciones públicas o el fomento de actuaciones privadas, previstas en el planeamiento, para la mejora, conservación y rehabilitación de zonas degradadas o de edificaciones en la ciudad consolidada”.

Ahora bien, como decíamos esta ampliación de los destinos de los recursos económicos de los Patrimonios Municipales de Suelo se encuentra matizada en la propia Ley. Afirmación ésta, en modo alguno gratuita, sino que por el contrario entendemos que la finalidad o destino recogido en el arto 75.2.d) para los recursos económicos que integran el Patrimonio Municipal del Suelo

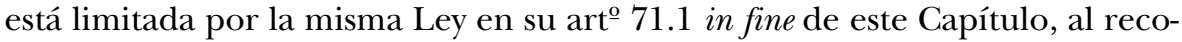
ger lo establecido en la norma estatal precedente de carácter básico, así el artº 71.1 in fine indica:

"Los ingresos procedentes de la enajenación o explotación del Patrimonio Municipal del Suelo deberán aplicarse a la conservación y ampliación de dicho Patrimonio."

La norma transcrita, a nuestro juicio, limita o cuando menos condiciona que el destino de los fondos del Patrimonio Municipal del Suelo puedan utilizarse para la finalidad indicada en el apartado d) del p.2, art ${ }^{\mathrm{o}} 75$, dado que si bien y en principio los apartados a) adquisición de suelo destinado a viviendas de protección oficial... b) conservación, mejora, ampliación y en general gestión urbanistica de los propios bienes del correspondiente patrimonio público y c) la promoción de viviendas de protección oficial (entendida sobre bienes integrados en el citado $\mathrm{Pa}-$ trimonio del precitado artículo), del citado artículo, son finalidades o destinos perfectamente encajables en lo que el art ${ }^{\text {o }} 71.1$ in fine denomina "conservación y ampliación de dicho patrimonio", no ocurre así con los que se recogen el apartado d) y todo ello sin perjuicio del carácter subsidiario de los destinos recogidos en los apartados b), c) y d) en relación al que tiene un carácter preferente según lo recogido en el apartado a) de ese artículo.

Pero llegados a este punto del estudio habría que detenerse en comprobar cuáles serían esos otros fondos que integrados en los Patrimonios Municipales del Suelo y no derivados de la enajenación y explotación de los bienes integrantes del citado Patrimonio pueden destinarse al cumplimiento de los destinos especificados en el apartado d) del p.2 art $^{\circ} 75$. 
Respuesta a esta cuestión la encontramos si nos detenemos en el precepto que la Ley de Ordenación Urbanística de Andalucía dedica para regular los bienes y recursos que integran los Patrimonios Públicos de Suelo, art ${ }^{\circ}$ 72, para de su examen comprobar cuáles son esos otros recursos económicos que no derivan propiamente de la enajenación o explotación de dicho Patrimonio y que forman parte de éste. A estos efectos se recoge en el apartado d) del precitado art $^{\circ} 72$ lo siguiente:

"Los ingresos obtenidos en virtud de la prestación compensatoria en suelo no urbanizable, de las multas impuestas como consecuencia de las infracciones urbanisticas, asi como cualesquiera otros expresamente previstos en esta Ley."

Por tanto, hasta aquí tenemos meridianamente claro que ningún reparo a que los fondos obtenidos por el Municipio por estos dos conceptos (multas por infracciones urbanísticas y prestación compensatoria en suelo no urbanizable) se integran en el Patrimonio Municipal del Suelo se podrán destinar sin limitación a la finalidad prevista por el apartado d) p.2. del art ${ }^{\circ} 75$ en tanto que son ingresos que obviamente no proceden de las operaciones de enajenación y explotación de los bienes del Patrimonio Municipal del Suelo.

Esta conclusión resulta si cabe más clara si tenemos en cuenta lo dispuesto en el art $^{\circ}$ 197.2 de la Ley de Ordenación Urbanística de Andalucía, al indicar:

"Los importes en concepto de sanciones, una vez descontado el coste de la actividad administrativa de inspección que reglamentariamente se establezca, se integrarán en el patrimonio público de suelo, destinándose especialmente a actuaciones previstas en el planeamiento, en equipamientos y espacios libres dentro de la ciudad consolidada".

Ahora bien, ¿qué otros recursos económicos integrados en el Patrimonio Municipal del Suelo por disposición de esta Ley no están afectados a lo que denomina el art 71.1 in fine "conservación y ampliación de dicho Patrimonio"?

Como decíamos, el arto 72 d) in fine de la Ley de Ordenación Urbanística de Andalucía indica “...así como cualesquiera otros expresamente previsto en esta Ley"

¿Cuáles pueden ser éstos?

De la lectura de la Ley llegamos a encontrar otro recurso económico no reseñado hasta ahora. En concreto, nos estamos refiriendo a lo dispuesto en 
el artº 30.2 de la Ley de Ordenación Urbanística de Andalucía, al tratar los Convenios urbanísticos de planeamiento.

Indica este artículo en su párrafo 2ㅜ․ "La cesión del aprovechamiento urbanístico correspondiente a la Administración urbanística, bien en suelo o cantidad sustitutoria en metálico según las condiciones que se establezcan en el Convenio, se integrarán en el patrimonio público de suelo correspondiente."

A continuación sigue diciendo este artículo: "En los casos en que la cesión del aprovechamiento urbanistico se realice mediante el pago de cantidad sustitutoria en metálico, el convenio incluirá..."

Es el supuesto de que la cesión de aprovechamiento que por Ley corresponde a la Administración se realice en metálico -cantidad sustitutoria- y no en terrenos o construcciones.

Se trata, por tanto, del recurso económico que la Ley de Ordenación Urbanística de Andalucía denomina “cantidad sustitutoria” por la cesión de aprovechamientos. Los importes que por tal concepto se generen ingresan en los Patrimonios Públicos de Suelo y, en principio, y a nuestro juicio, no estarían afectados a la finalidad prevista en el art ${ }^{\circ} 71.1$ in fine de esta Ley.

Abundando más en esta idea hay que indicar que la Ley no entiende esta cantidad como el resultado de una enajenación de aprovechamientos, la Ley lo califica como algo distinto, "sustitución”, término diferente a lo que puede ser enajenación o transmisión. Así utiliza al tratar de estos recursos términos como los de "cantidad sustitutoria" "compensaciones monetarias sustitutivas".

Evidentemente no podemos desconocer que esta terminología obedece al cambio legislativo operado por la Ley 6/98, de 13 de abril sobre Régimen del Suelo y Valoraciones en cuanto al régimen urbanístico de la propiedad inmobiliaria sobre el que se impuso con la vigencia de la legislación urbanística de los primeros años de los 90 .

Pues bien, siguiendo con nuestro razonamiento y concluyendo, entendemos que aunque pueda parecer, en principio, extraño, la conclusión sería la siguiente: si se entregan a la Administración los aprovechamientos de cesión en terrenos y éstos posteriormente a su incorporación en el Patrimonio Público de Suelo se enajenan, los ingresos que se obtengan por ello si quedan afectados a "la conservación y ampliación del Patrimonio Municipal del Suelo" pero si lo que se entrega desde el principio en sustitución de estos aprovechamien- 
tos es una cantidad en metálico, ésta no queda afectada a esta finalidad. Es a ésta y no a otra la conclusión a que se llega de la lectura de los preceptos de la Ley de Ordenación Urbanística de Andalucía y no es labor de la Administración, obligada a aplicar las Leyes, dejarla de aplicar por enjuiciar los planteamientos de ésta a priori de extraños o incoherentes.

Decimos que es a esta conclusión en principio a la que nos lleva porque también puede entenderse que ha sido una opción del legislador autonómico andaluz que en el marco de sus competencias de desarrollar los preceptos básicos del Estado y en el ánimo de seguir potenciando la institución de los Patrimonios Municipales del Suelo y de primar su función como institución eficaz para intervenir en el mercado de suelo, abaratando el precio de éste, refuerce los recursos que se dedican a esta finalidad garantizando su afectación a la conservación y ampliación de dicho Patrimonio sin que por contra esta opción suponga menoscabo o minusvaloración de las otras finalidades sociales que pretende conseguirse también a través de esta Institución y que poco o nada tendrían que ver con los bienes integrantes de dicho Patrimonio.

Y decimos que ha podido ser una opción del legislador autonómico, constitucionalmente legitimado para ello, porque del estudio comparado de otras legislaciones autonómicas, actualmente vigentes, se pueden extraer opciones totalmente distintas de este planteamiento, si bien éstas pueden agruparse en dos grandes bloques. Pasamos a estudiarlas:

1.- Las legislaciones autonómicas de corte más liberal, como la de las Comunidades Autónomas de Cantabria, Galicia, Castilla y León, Asturias, optan por el modelo caracterizado por destinar los bienes y fondos económicos que integran los Patrimonios Públicos de Suelo a una finalidad amplia, entendida, por tanto, ésta como no limitada a lo que puede ser considerado "conservación y ampliación de dichos patrimonios".

Así la Ley de Urbanismo de Castilla y León, Ley 5/1999, de 8 de abril, indica en su art" 125 dedicado a los "destinos del Patrimonio Municipal del Suelo" lo siguiente:

"Los bienes de los Patrimonios Públicos de Suelo, los fondos adscritos a los mismos, asi como los ingresos obtenidos por su enajenación, deberán destinarse necesariamente a alguno de los fines de interés social previsto en el Planeamiento Urbanístico: ...", enumerándose a continuación una serie de destinos, entre los que destacan aquellos que no son sólo los de conservación y ampliación del Patrimonio Municipal del Suelo. 
La Ley 9/2002, de 30 de diciembre, de Ordenación Urbanística y Protección del Medio Rural de Galicia indica en cuanto a los destinos en su art $^{\circ}$ 176.1:

“.... los ingresos obtenidos mediante la enajenación de parcelas o del aprovechamiento que corresponda a terrenos de titularidad municipal, se destinarán a los fines previstos en el $\underline{\text { art }^{\circ} 177}$ de la presente Ley”.

Y el artº 177 enumera como igualmente hacía la Ley de Castilla y León una serie de destinos que exceden de lo que es la conservación y ampliación del Patrimonio Municipal del Suelo; así se indica:

"Actuaciones públicas dotacionales, sistemas generales u otras actividades de interés social", "conservación y mejora del medio ambiente, del medio rural y del patrimonio cultural edificado..."

La Ley 3/2002, de 19 de abril, de Régimen del Suelo y Ordenación Urbanística del Principado de Asturias al regular esta materia recoge en su $\operatorname{art}^{\circ}$ 163 "Destinos", lo siguiente:

"Los bienes y derechos económicos integrantes de los patrimonios públicos de suelo necesariamente deberán destinarse a lo que al respecto esté previsto en los instrumentos de ordenación urbanistica, en atención a los siguientes fines de interés social: ...incluyéndose además los propios de conservación y ampliación del Patrimonio Municipal del Suelo, los de:

e) Ejecución de dotaciones urbanísticas públicas, incluidos los sistemas generales y locales", que nada tendrían que ver con lo que es la conservación y ampliación de dicho patrimonio.

En iguales términos se pronuncia la Ley 2/2001, de 25 de junio, de Ordenación Territorial y Régimen Urbanístico del Suelo de Cantabria, en sus art $^{\circ} 229.3$ y 233.

2.- En la otra opción, es decir, aquellas legislaciones que conceptúan a los Patrimonios Municipales del Suelo como institución válida, para intervenir preferentemente en el mercado de suelo. Así, encontramos la Ley 2/1998 de Ordenación del Territorio y de la Actividad Urbanística de Castilla-La Mancha, que indica respecto al tema que tratamos en su arto 76.2 párrafo 2 lo siguiente: 
"Los ingresos obtenidos mediante enajenación de terrenos incluidos en los patrimonios públicos de suelo o sustitución por su equivalente económico de la cesión relativa..., deberán aplicarse a la conservación y ampliación de dichos patrimonios".

A continuación se regula en el art ํ $^{-} 79$ el destino de los bienes integrantes de los Patrimonios Municipales del Suelo, una vez incorporados al proceso urbanizador y edificatorio, es decir, de los terrenos e inmuebles y no de los fondos económicos cuya afectación es la indicada en el primero de los artículos citados.

Esta opción también es la elegida por la Ley 15/2001, de 14 de diciembre, del Suelo y Ordenación Territorial de Extremadura.

Esta Ley en su artículo 88 párrafo segundo in fine dice:

“... Los ingresos obtenidos mediante enajenación de terrenos incluidos en los patrimonios públicos de suelo o sustitución por su equivalente económico de la cesión relativa a la parte de aprovechamiento urbanistico perteneciente a la Administración deberán aplicarse, a la conservación y ampliación de dichos patrimonios".

Abundando más en esta finalidad, en el apartado 2 del arto 92 de esta Ley se especifica: "Los recursos que obtenga la Administración por la aplicación de los bienes a los fines enumerados en el párrafo anterior y, en general, por su gestión, administración y disposición, tienen la consideración de ingresos específicos afectados a fines determinados, a los efectos de lo dispuesto en la legislación reguladora de las Haciendas Locales y deberán integrarse en el patrimonio público de suelo.

Y en su párrafo $3^{\circ}$ :

"Los Ayuntamientos están obligados a destinar dichos fondos, a través de sus Presupuestos, a los fines de los Patrimonios Públicos de Suelo, y especialmente a: ... (enumera una serie de destinos que constituyen lo que propiamente es gestión, administración, conservación, urbanización, en definitiva, ampliación de dicho patrimonio).”

Hasta aquí un breve resumen de las distintas regulaciones autonómicas en esta materia.

En nuestra Comunidad Autónoma, la Ley de Ordenación Urbanística de Andalucía, opta, como ya decíamos, por una posición que ante los dos modelos claramente definidos podríamos calificar de intermedia en donde la obli- 
gación de reinvertir en el propio patrimonio -conservación y ampliación-, los ingresos derivados de la gestión de los bienes que lo integran, obligación, principio básico y característica de la Institución de los Patrimonios Municipales del Suelo desde la Ley del Suelo de 1956, aparece limitada únicamente a los ingresos dimanantes de la enajenación y explotación de los bienes integrantes de los patrimonios públicos de suelo y no, por tanto, afecta a los otros recursos económicos que por disposición legal pueden integrarse en los $\mathrm{Pa}$ trimonios Municipales del Suelo.

Por tanto, llegados a este punto, hay que concluir sobre la viabilidad legal en el marco de la legislación urbanística de nuestra Comunidad de que con cargo a estos otros ingresos de los Patrimonios Públicos de Suelo, es decir, a los derivados de la "sustitución económica" de los aprovechamientos que por Ley corresponden a la Administración; a los ingresos provenientes de las multas por infracciones urbanísticas y a los derivados de la prestación compensatoria en suelo no urbanizable, puedan afrontarse las operaciones que puedan calificarse o que se englobe en lo que se denomina por el apartado d) del art $^{\circ} 75$ de la Ley de Ordenación Urbanística de Andalucía "la ejecución de actuaciones públicas o el fomento de actuaciones privadas, previstas en el planeamiento para la mejora, conservación y rehabilitación de las zonas degradadas o de edificaciones en la ciudad consolidada".

Ahora bien, también esta viabilidad no es absoluta y debe ser también matizada en el sentido que ya apuntábamos, dado que tal como indica el art $^{\circ}$ 75.2.a) estos recursos en la medida en que englobados en los resultantes de la gestión de los Patrimonios Públicos de Suelo gozan, en cuanto a su destino, de un carácter preferente para la finalidad de "adquisición de suelo destinado a viviendas de protección oficial u otros regímenes de protección pública”. Por lo tanto, sólo con carácter excepcional deberán admitirse estos otros destinos para estos otros recursos.

Finalmente indicar, como ya recogíamos al principio de este comentario, que hemos conocido que esta opinión que recogemos en este artículo no es pacífica y que hay ya alguna opinión diferente ante este planteamiento ${ }^{1}$ que manifiesta que el art ${ }^{\circ} 71$, párrafo 2 in fine, es irrelevante. Es más, indica, que "constituye un error o defecto de redacción". Sigue diciendo que "no tiene sentido que al hablar especificamente de la posibilidad de acudir al crédito y de constituir hipotecas sobre los bienes del PMS, se hable de los ingresos en general y no de los ingresos proce-

\footnotetext{
${ }^{1}$ El Consultor no ${ }^{\circ} 11,15$ de junio de 2003, Consultas.164.
} 
dentes del crédito a que se refiere el apartado. Tampoco tiene sentido que afirmación tan general y programática se incluya al hablar de lo que es pura gestión de dicho patrimonio y de «tapadillo»".

Sigue diciendo:

"La Ley de Ordenación Urbanistica de Andalucía, termina diciendo, establece unos fines genéricos (art ${ }^{\circ}$ 6), y unos fines concretos ( art $^{\circ}$ 75) en cuanto a los terrenos y construcciones y en cuanto a los ingresos y a ellos hay que estar. Por otra parte, del texto de la Ley no se deduce un criterio finalista en cuanto a los ingresos de las compensaciones y las multas, salvo el que contiene para éstas el art ${ }^{\circ} 197$ ”.

Error o no, defecto de redacción o no, lo cierto es que el artº 71 , párrafo 2 in fine es bastante explícito y dice lo que dice.

Tampoco creemos que nuestra opinión se haya podido ver influenciada por el planteamiento, que es lícito confesar que compartimos, de entender esta institución, y de ahí nuestra defensa a ultranza, como un verdadero y eficaz instrumento de la Política de suelo y viviendas de los Municipios, ahora ya también de las Comunidades Autónomas, sin que finalidades abstractas o bajo la configuración de conceptos jurídicos indeterminados "la ejecución de actuaciones públicas", "fomento de actuaciones privadas"... pueda situarse en pie de igualdad con el resto de finalidades primigenias del Patrimonio Municipal del Suelo, difuminando o volatilizando éstas e incluso llegando en el peor de los casos a hacer desaparecer una institución creada para intervenir en el mercado de suelo a fin de que con una oferta de suelo suficiente en mano pública combatir la especulación y por ende la crecida imparable de los precios de la vivienda. 